\title{
Painting beyond the stretcher
}

\author{
SANNE KOELEMIJ
}

\section{Abstract}

This article is an extract of my Honours exegesis, Boxes of Contrast and Painting Beyond the Stretcher, completed within the Painting Department at the ANU School of Art, 2015. The article focuses on my Painting Beyond the Stretcher research, which investigates the relationship between colour, shape and materiality through the language of abstract painting. I explore the way shape, colour and material relate to each other through intuitive and responsive processes of paint application. My fundamental concerns are how these elements can construct ambiguous pictorial spaces and therefore create visual tensions within the pictorial order of marks applied. This project also explores how non-traditional painting materials can aid this, with contextual research that includes contemporary artists who work with similar ideas; such as Katharina Grosse and Jessica Stockholder. This research informs how my studio practice contributes to contemporary art and the field of an expanded notion of painting.

My Honours research explored colour, shape and materiality: three broad elements related to most visual thinking. I began with a curiosity about the possibilities of colour, particularly saturated colour, and the vibrant relationships created when complementary opposites are paired together. I am interested in how colour can operate as a form, or shape, within a non-representational composition. Through my research, I found the work of Mark Rothko influential in establishing how colour can exist as its own subject in painting, outside of any representational meaning. ${ }^{1}$ Early in my Honours year, I realised that my research would have to develop through experience. This is because I was not referencing or deconstructing any representational imagery that I could use as a guide for abstraction. Abstraction is derived in my work from each individual response to a material, colour or shape, as they arise in my painting process.

1 Mark Rothko, 'Objective Impressionism', in The Artist's Reality: Philosophies of Art, ed. Christopher Rothko (New Haven: University Press, 2004), 38-41. 


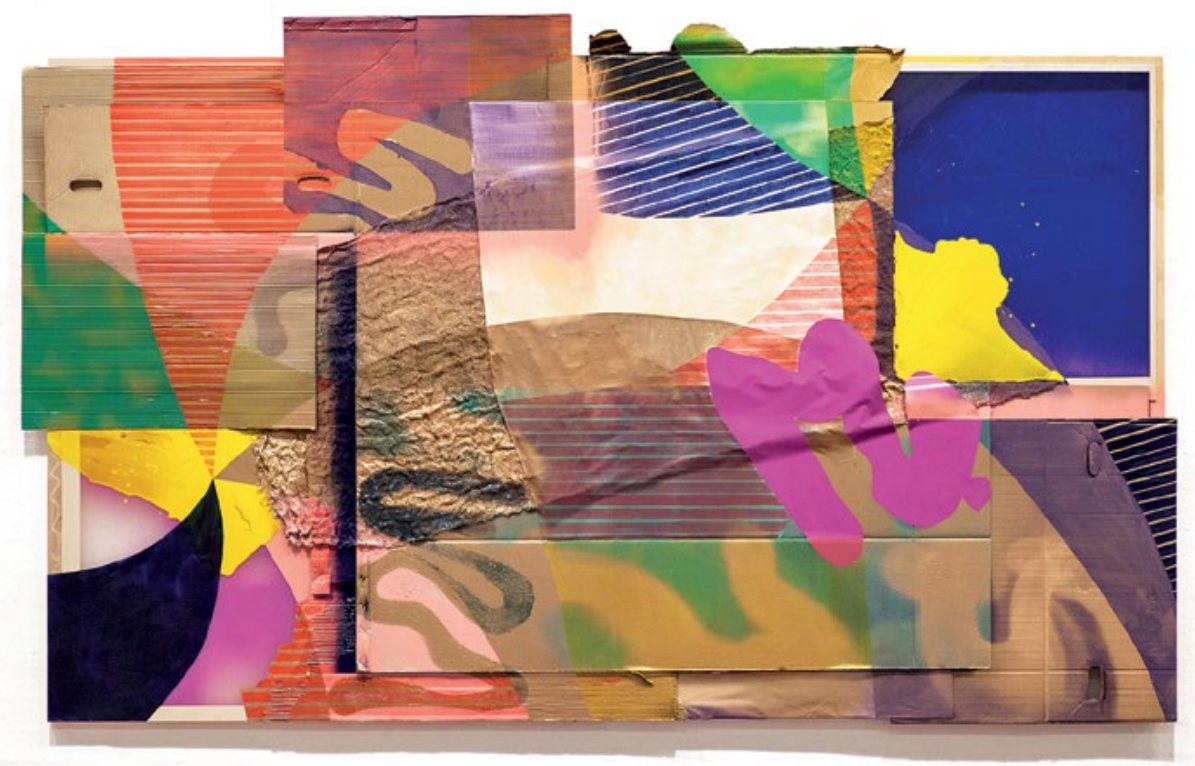

Figure 1: Sanne Koelemij, Doubled My Mark, 2015. Acrylic on mixed media, $1910 \times 3039 \mathrm{~mm}$.

Photo: Andy Mullens.

I began my paintings by constructing the 'canvas'. I created my canvases by weaving materials with interesting textures and shapes that I found or collected. Some examples are cardboard, hessian, plastics, fabrics and wood. I folded, cut, ripped and glued these materials together until they reached a textural balance. I then mapped a focal point and created a spiral formation projecting outwards from this central space. I used the segments to build up layers of colour using acrylic and spray paint. Each action, or mark, I made was intuitive and responsive by weighing up the elements in each composition after a gesture was placed on the surface. As I layered each body of colour, the materials of the canvas began to inform the way I applied paint. For example, in Doubled My Mark the fluorescent pink lines were absorbed into the materials (cardboard and hessian), which dulled the colour (Fig. 1). As a response, I introduced a pink spray-painted mark on the bottom left of the painting, and a collaged mark in the middle-right of the work. Both hues create a 'push-pulling' effect and aid depth in the painting as the order in which marks are made is unclear. 


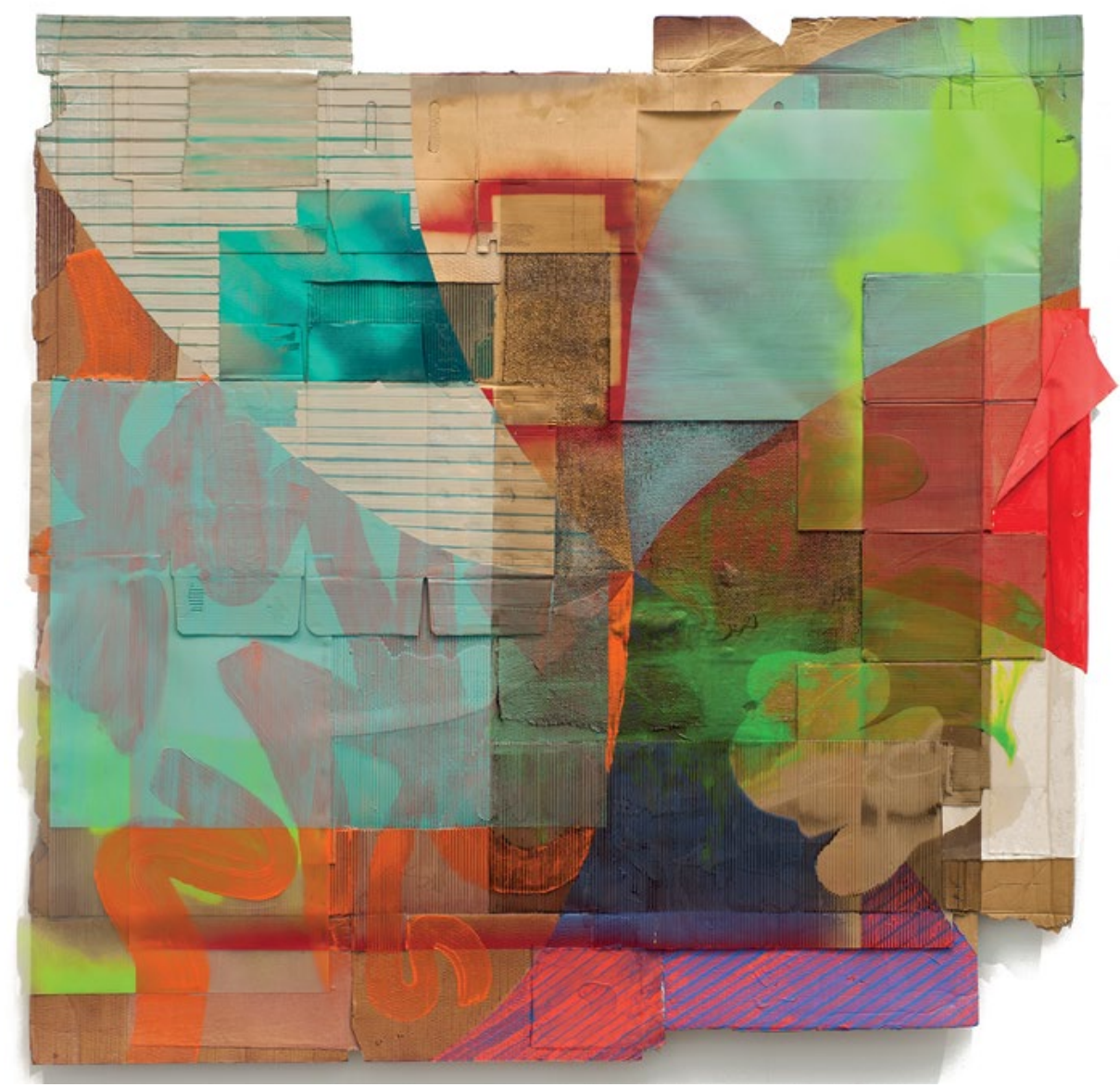

Figure 2: Sanne Koelemij, Untitled (Frankenstein), 2015. Acrylic on mixed media, $2000 \times 2050 \mathrm{~mm}$.

Photo: Luis Power.

My transformative processes create balance and symmetry between the unified materials in the 'canvas' and the abstracted areas of colour. When and where a painted mark is applied, the colour of the mark unifies the variety of textures it covers. In reverse, the materials in the canvases visually fragment a painted mark. This opens up a dialogue between the painted material and its own spatial charactercreating a visual tension between representation, through the recognition of physical materials, and illusion, created by the choice of colours and painted marks that disrupt the pictorial space. The materials used in my canvases are present as matter in themselves but also forgotten, or forced to become an illusion, by the diversity of colour and choices in mark making. In Untitled (Frankenstein), the red segment on the right-hand side of the painting is constructed using layers of cardboard and cotton fabrics (Fig. 2). The entire shape was covered in transparent red acrylic, but 
in the middle of the segment I mimicked a shadow line in fluorescent green to create the illusion of a non-existent form. The understanding of form is therefore disrupted and the pictorial space becomes difficult to comprehend.

I use non-traditional materials in my canvases as a springboard to create a dialogue between surface construction and painterly gestures. The various contrasts between forms created through material in my canvases and layers of colour fields create a narrative for the way a work is constructed, and the journey I have taken with it. I am interested in the experience that this journey can produce for the viewer as well as the artist.

The idea that marks create narrative is extensively discussed in the field of nonrepresentational abstraction. For example, a gestural mark created by the bodily movement of the painter draws association to the American post-war movement Abstract Expressionism; expressive narratives of paint exerted through gestures onto canvas. ${ }^{2}$ In a contemporary context, the bodily movement of the painter can suggest different associations other than emotional tones or meanings. Contemporary artist, Katharina Grosse, uses bodily gestures to construct a physical, painterly space onto gallery walls. ${ }^{3}$ Grosse's gestures create a dialogue between her and the composition, constructing a non-representational narrative rather than presenting a type of subjective emotion. ${ }^{4}$ The narrative of marks are therefore immersive and responsive to materials where painterly gesture functions to create shapes defined against each other by colour.

Another context for my research into narrative is the internationally recognised artist Jessica Stockholder. Her artworks are hybrid, three-dimensional paintings where her supports are constructed by 'everyday' materials. For example in the work Untitled (Sailcloth Tears), 2009, Stockholder uses a wooden surfboard, metal, wire, plastic, a light bulb, carpet, fabric tape, blue foam and more to construct the 'canvas'. Stockholder describes the experience of her work as 'walking through this fiction', which reflects the engagement of her work as a type of journey, or the narrative, taken with the materials she uses. ${ }^{5}$ I thought about this evaluation of narrative, and Grosse's work, reflecting on the experience I wanted to achieve in my research.

\footnotetext{
2 Stephen Little, ... isms: Understanding Art (London: Herbert Press, 2004), 122.

3 Norr and Grosse, Third Man Begins Digging Through Her Pockets, accessed August 25, 2015, video interview online at: www.youtube.com/watch?v=MIy9po_ZLKM.

4 Ibid.

5 Full quote: 'She describes an experience of her work as "walking through this fiction". The work flows, takes sudden leaps, makes visual rhymes with materials, surface, colours - the viewer, wandering out of curiosity, but lead by the eye ...' Adrian, Searle, 'Unbound,' in Unbound: Possibilities in Painting, ed. Adrian Searle and Greg Hilty (London: Hayward Gallery, 1994), 13.
} 


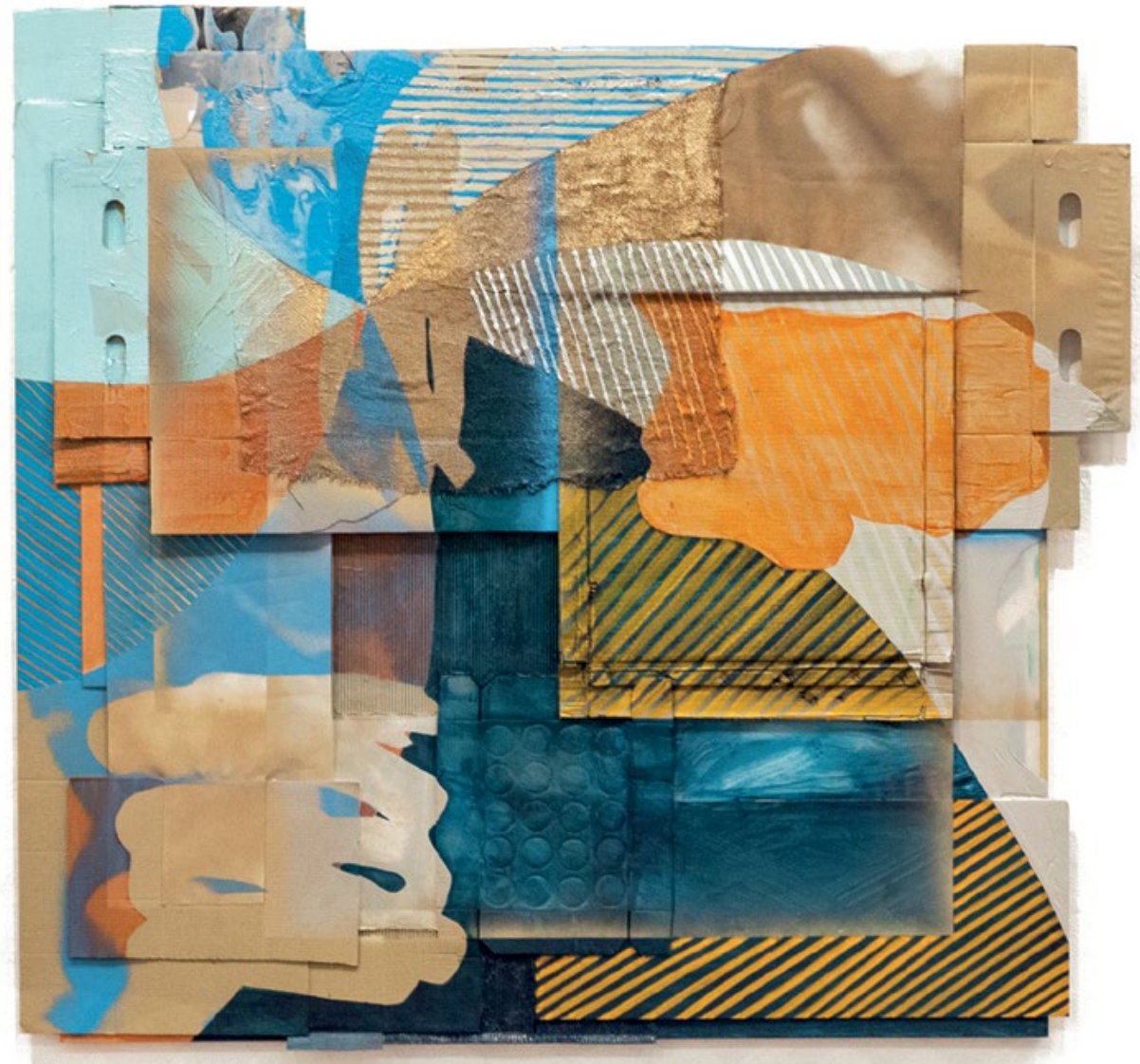

Figure 3: Sanne Koelemij, My Mark is a Shape, is an Object, is a Mark, 2015. Acrylic on mixed media, $1940 \times 2050 \mathrm{~mm}$.

Photo: Andy Mullens.

Like Stockholder and Grosse, my research responsively engages in non-conventional critique of traditional painting. For example, Grosse challenges these ideas by using spray paint instead of oils and non-traditional surfaces like gallery walls or piles of dirt. I set out to explore similar complexities regarding painting's conversation with the 'everyday' via the materials in my work. The way I use everyday materials activates new possibilities of meaning inside the work and the associations these materials might trigger beyond the frame. The material choices I made with the construction of my canvases needed to have a purpose or function in our 'everyday' environment. To aid this connection, I chose to leave each material in the size and relative shape I found them in rather than cutting the materials to fit on a standard four-sided stretcher (Fig. 3). I enjoy the fact that the materials I use present a more worldly engagement, creating an emotional experience through our recognition of the function that a material has in our environment. These materials also function as a non-representational link to the world, allowing me to construct abstract paintings. 


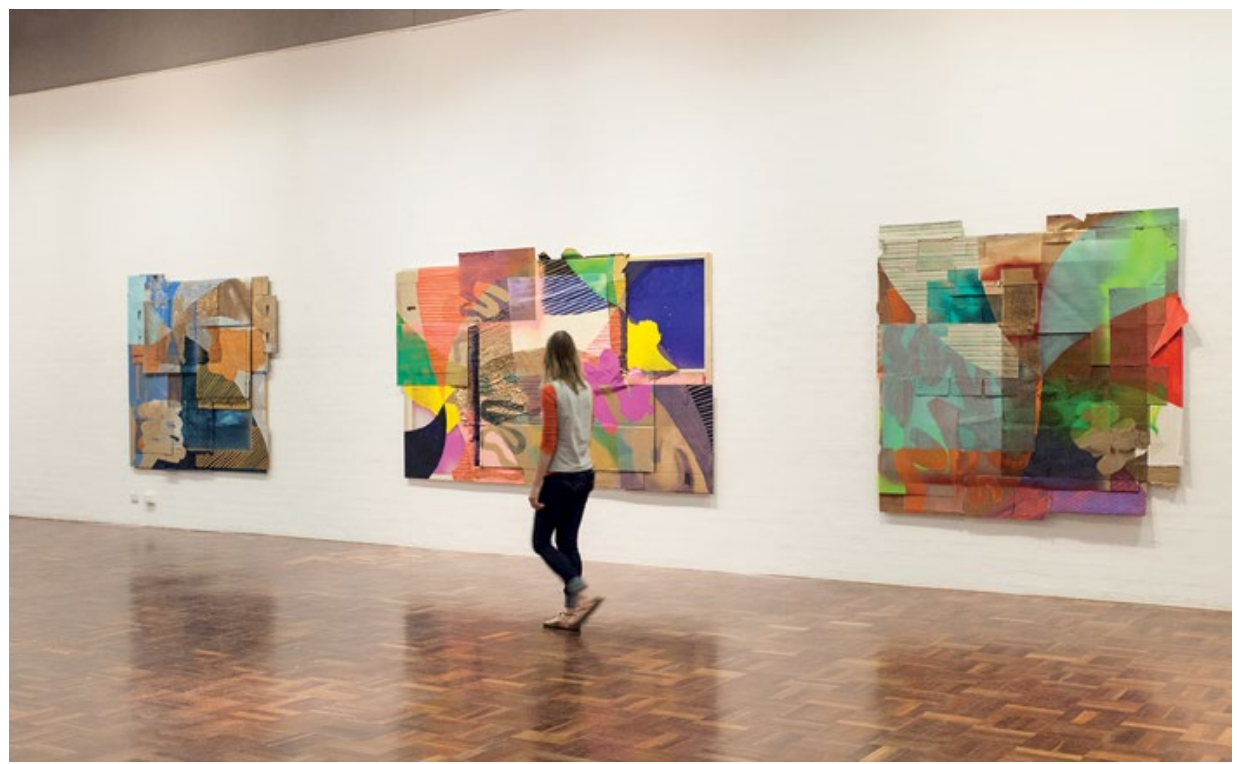

Figure 4: (Installation image) Sanne Koelemij, Painting Beyond the Stretcher, 2015. Acrylic on mixed media, dimensions variable. Photo: Andy Mullens.

The language of abstraction and the artist's narrative are what generates the 'experience' of an artwork. Nothing beats pushing, pouring or dragging fluid material, like paint, up and down on a canvas and I hope the viewer experiences the same pleasure and energy that I do when making these works. I am, therefore, focused on the mood of enjoyment and pleasure, and how gesture, scale, colour and composition can elicit a range of emotional responses. For example, in the installation image (Fig. 4), it is evident that the scale of my work is larger than human height, creating colour field landscapes that heighten the impact of the emotional experience of each work.

Using and maintaining the integrity of the materials in these paintings allows for the shapes on the surface to be recognised as part of our everyday and brings the 'everyday' into the gallery context. Throughout my Honours research, I feel that I have made a contribution to the field of an expanded notion of painting. I used techniques and processes influenced by various contemporary artists, such as Katharina Grosse and Jessica Stockholder, as inspiration in developing my own painting language. Like these artists, I situate my practice-led research within this field, using nontraditional materials to fragment painterly gestures. In so doing, I am not trying to present a challenge to the use of traditional painting materials. Instead, in a similar spirit to Grosse and Stockholder, I am using materials to formally create tension between painted and constructed material abstract fields. 


\section{Bibliography}

Batchelor, David (ed.). (2008). Colour. London: Whitechapel Gallery.

Grosse, Katharina, \& Watkins, Jonathan. (2002). 'How to Start and Stop Painting'. In Katharina Grosse (pp. 24-35). Wolfratshausen: Edition Minerva Hermann Farnung.

Grynsztejn, Madeleine (ed.). (2005). The Art of Richard Tuttle. New York: Distributed Art Publishers Inc. and San Francisco Museum of Modern Art.

Hardin, C.L. (1988). 'Color for Philosophers'. In Color for Philosophers: Unweaving the Rainbow (pp. 39-42). Indianapolis: Hackett Publishing Co.

The Kaleidoscopic Turn. (March-August 2015). Melbourne, Vic: National Gallery of Victoria.

Kristeva, Julia. (1980). Desire in Language (Alice Jardine, Leon S Roudiez \& Thomas Gora, Trans.). Los Angeles: University of California Press.

The Light Show. (April-July 2015). Sydney, NSW: Museum of Contemporary Art.

Little, Stephen. (2004). ... isms. Understanding Art. London: Herbert Press.

Myers, Terry R. (ed.). (2011). Painting. London: Whitechapel Gallery.

National Gallery of Victoria. 'The Kaleidoscopic Turn: From the NGV Collection'. Retrieved from www.ngv.vic.gov.au/exhibition/the-kaleidoscopic-turn (accessed 23 August 2015).

Norr, David \& Grosse, Katharina. (2013). Katharina Grosse: Third Man Begins Digging Through Her Pockets. Cleveland: Museum of Contemporary Art. Retrieved from www.youtube.com/watch?v=MIy9po_ZLKM (accessed 25 August 2015).

Rothko, Mark. (2004). 'Objective Impressionism’. In Christopher Rothko (ed.), The Artist's Reality: Philosophies of Art. New Haven: University Press.

Searle, Adrian. (1994). 'Unbound'. In Adrian Searle and Greg Hilty (eds), Unbound: Possibilities in Painting (pp. 13-17). London: Hayward Gallery.

Selzer, Rob. (2015). 'Self-Expression Should be Chemical-Free', New Philosopher Magazine, February-April, 100-102. 
Stockholder, Jessica. (1995). 'Lynne Tillman in conversation with Jessica Stockholder' In Jessica Stockholder (pp. 10-14). London: Phaidon Press.

Thompson, Tatyana. (2014). Mark Rothko: The Art of Conservation. Los Angeles: Museum of Contemporary Art tv. Retrieved from www.youtube.com/ watch?v=GiWvvJcmvJU (accessed 8 May 2015). 
This text is taken from The ANU Undergraduate Research Journal, Volume Eight, 2016, edited by Daniel McKay, published 2017 by ANU eView, The Australian National University, Canberra, Australia.

dx.doi.org/10.22459/AURJ.08.2016.11 